\title{
Tensile and compressive behaviour of additively manufactured AlSi10Mg samples
}

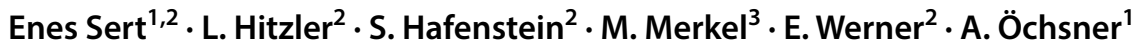

Received: 6 September 2019 / Accepted: 24 March 2020 / Published online: 3 April 2020

(c) The Author(s) 2020

\begin{abstract}
Laser powder-bed fusion has become one of the most important techniques in additive manufacturing. For guaranteeing the possibility of manufacturing highly specialized and advanced components, currently intensive research is carried out in this field. One area of this research is the material-specific macroscopic anisotropy, which is investigated in our work by comprehensive static mechanical experiments. The material which was tested within this study was the precipitation-hardenable AlSi10Mg alloy, with the focus on installation space orientation. Tensile and compression tests were performed, the results for the Young's modulus in compressive loading exceeded the previously known values of this material in tensile loading and achieved values of up to $79.8 \mathrm{GPa}$. As a result of this investigation, a chemical spectroscopic analysis was undertaken and from the actual chemical composition, a relative density of $99.86 \%$ of the samples was determined.
\end{abstract}

Keywords Powder bed $\cdot$ Selective laser melting $\cdot$ Tensile test $\cdot$ Compression test $\cdot$ Spectral analysis $\cdot$ Precipitation hardening $\cdot$ Build direction

\section{Introduction}

The selective laser melting technique is closely related to the laser-sintering process and it develops further on this basis. Laser sintering is one of the first AM technologies in which raw metal powder was used [1]. Initially, polymers were introduced as binding media, connecting the unmolten metal powder particles and created a green part. Additional infiltration with a low-melting material, usually copper or bronze, was required to obtain adequate density and mechanical properties [2,3]. In the selective laser melting technique, the building process takes place in layers, with the working platform being moved downwards step by step (Z-direction). To prevent thermal distortion, the substrate plate of aluminium alloys is usually heated, higher preheating temperatures

Enes Sert

enes.sert@hs-esslingen.de

1 Faculty of Mechanical Engineering, Esslingen University of Applied Sciences, Kanalstrasse 33, 73728 Esslingen, Germany

2 Institute of Materials Science and Mechanics of Materials, Technical University of Munich, 85748 Garching, Germany

3 Institute for Virtual Product Development, Aalen University of Applied Sciences, 73430 Aalen, Germany lead to grain coarsening due to lower solidification rates and, even more detrimental, to an increased solubility of gases in the melt, promoting pores in the fabricated component [4-6]. Fabrication without preheating yields higher hardness and strength, but at the cost of higher residual stresses and an increased likelihood of cracks [7]. The powder layer thickness ranges between 20 and $100 \mu \mathrm{m}$, depending on the laser capabilities and the requirements on productivity and accuracy. During the manufacturing process, the unexposed powder remains loose. The loose powder in the so-called powder bed serves on the one hand as protection against welding spatter for the component and on the other hand, it acts as support for the production of thin-walled elements, components with overhangs, or for the stacking of several components on top of each other. Support structures between the working platform and the component add structural rigidity and ensure a good heat transport between the component and the platform, with excess heat being dissipated via the thermal management system (Fig. 1), [8, 9]. For the successful implementation of selective laser melting in industrial applications, the knowledge and the understanding of the characteristic and process-related properties of the generated components are essential. The manufacturing process includes numerous direction-related influencing factors, such as: 


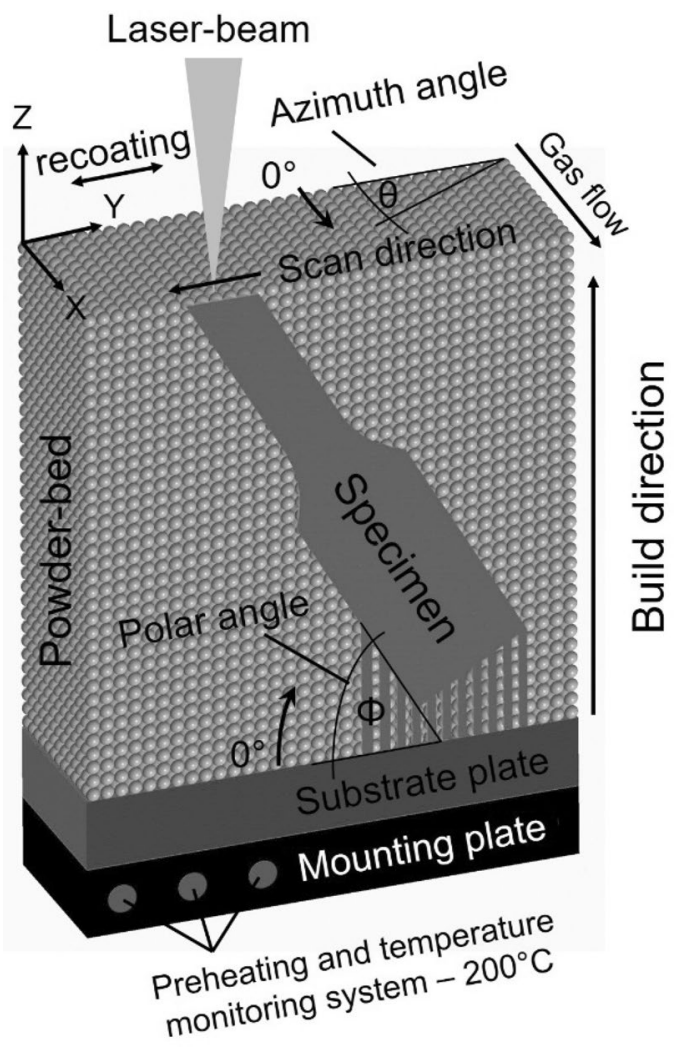

Fig. 1 Production conditions with installation space temperature, polar angle and azimuth angle

- The applied exposure pattern per individual layer with successive rotational increments of subsequent exposure patterns.

- Bidirectional application of the powder layer along one distinct translation path, including the flattening and compression of the powder layers beneath.

- The thermal influence of the preheated substrate plate and the incremental loss of influence due to increasing distance between the thermal regulation and active layer in the course of the process, associated with a potential alteration of the thermal environment present around the melt pool.

- The position dependent heat input via laser irradiation from above.

- The directional gas flow and the deviations in the layer quality by distinct agglomeration of weld splashes [1012].

These explained points are the main reasons why an anisotropic material behaviour and position induced deviations of the manufactured components may be present [13]. One possibility to address the anisotropic effects of titanium alloys is the addition of peritectic-forming elements. The resulting $\alpha$-phase is not always related to the orientation of the parent $\beta$-phase and this leads to significant texture reductions and equiaxed microstructures [14]. The incorporation of nanoparticles into aluminium alloys results in large columnar grains and avoids cracks in the additive production of high-strength aluminium alloys. These nucleants promote fine grain formation, which leads to higher strength and reduces the anisotropic effects [15]. Process conditions play a role, but more importantly in the case of the investigated Al-Si alloys, which unlike iron-, nickel- or titanium-based alloys do not show a noteworthy anisotropy in the single crystal (Zener factor of $\sim 1.2$ ), the macroscopic anisotropy is governed by the interconnection of scan tracks and layers and the eutectic solidification of the alloy [16]. Due to the high cooling rates of $10^{6}-10^{8} \mathrm{~K} / \mathrm{s}$ of the SLM process, SLM materials have extremely fine microstructures, which lead to excellent static mechanical properties in materials that do not cause stress cracks at high cooling rates. As a result of the high energy densities, the metal powder particles are completely melted and almost completely dense parts are obtained [17]. In the recent years, numerous studies have been carried out on the microstructure, the mechanical properties and the corrosion behaviour of selective laser-melted $\mathrm{Al}$ components. For example, a systematic investigation of the microstructure and corrosion properties of Al-Si alloys have been carried out by Zhang et al. [18-21]. The influence of the scanning strategy and heat treatment on the stress and fatigue properties was investigated by Suryawanshi et al. [22]. Jiang Bi et al. [23] investigated the optimal SLM process parameters of the $\mathrm{Al}-\mathrm{Zn}-\mathrm{Sc}-\mathrm{Zr}$ alloy with regards to geometric properties and surface topographies.

For determining the fluctuation in the static mechanical properties of additively manufactured samples, AlSi10Mg specimens with different inclinations and orientations were produced for our study. To prevent possible superposition of anisotropy and inhomogeneity effects, a secondary artificial aging treatment was employed $\left(170{ }^{\circ} \mathrm{C}\right.$ for $\left.4 \mathrm{~h}\right)$ as proposed in [24], eliminating the inhomogeneity caused by varying precipitation-hardening stages along the built height. LPBFAlSi requires longer solution annealing times of up to $2 \mathrm{~h}$ for the microstructure to stabilize. During this time, the $\alpha-\mathrm{Al}$ grains coarsen significantly and the finely dispersed Si segregations agglomerate to larger Si precipitates, preferably located at the heat-affected zones in the material at as-built condition. While these larger Si particles mostly eliminate the directional weakening, the $\mathrm{Si}$ segregations cause in the as-built condition, they are very large to contribute to the material's strength. Previous experiments showed the necessity of this treatment method, because otherwise the samples break predominantly at the specimens upper half and the values are, therefore, only conditionally meaningful $[24,25]$. It should be mentioned here that the heat treatment is not the focus of this study and further details can be found here [26-28]. Subsequently, the residual porosity was 
determined using the Archimedes' principle and tensile and compression tests were performed. The special feature of this study is the direct comparison between the tensile and compression tests. Due to the selected width/length ratio of 1:3 for the compression tests, a complete compression test with determination of the Young's modulus, yield strength and compressive strength should be carried out. To the best of the author's knowledge, this study is the first to provide a direct, directional comparison between tensile and compression modulus of elasticity and tensile and compression yield strength of AlSi10Mg.

\section{Experimental methods}

\subsection{Manufacturing conditions}

A SLM 280HL machine (SLM Solution GmbH, Lübeck, Germany) equipped with a $400 \mathrm{~W}$ ytterbium fiber laser was employed for the production of the AlSi10Mg samples. The laser beam diameter at the focal point was $80 \mu \mathrm{m}$ and the installation space had a size of $280 \times 280 \times 320 \mathrm{~mm}^{3}$. An inert environment was realised with argon, with the residual oxygen content being kept below $0.1 \%$, and the substrate plate was held at $200{ }^{\circ} \mathrm{C}$ during the production process. It should be mentioned that, depending on the component to be built, the effectiveness of the heat transport via thermal coupling, the molten bath and the sample material to the supporting structure varies. Given the fact that the powder bed acts like insulation compared to solid metal, due to its thermal conductivity being magnitudes lower, the thermal coupling is primarily governed by the interaction between the regulation system in the mounting plate and the component, connected via the substrate plate and the support structure. The cooling rate from layer to layer is not constant and the effective temperature of the actively fabricated layer can deviate from the preset temperature of the installation space, with this effect being emphasised with increasing height of the component. Previous experiments exhibited a resulting stationery temperature of $130{ }^{\circ} \mathrm{C}$ in the powder bed, measured $10 \mathrm{~mm}$ above the substrate plate, at a pre-set temperature of $200{ }^{\circ} \mathrm{C}$ [25]. Hence, an effective installation space temperature of $130{ }^{\circ} \mathrm{C}$ is assumed. For the samples, the metal powder from SLM Solutions $\mathrm{GmbH}$ with a particle size of 20-60 $\mu \mathrm{m}$ was used and a layer thickness of $50 \mu \mathrm{m}$ was adjusted. The samples were produced in one build job with an oversize of $2 \mathrm{~mm}$ in the test diameter, which was machined and polished to size after heat treatment. Due to polishing, the surface roughness varies, but it is within the tolerance range. For meeting the control requirements with are related to high relative density for the core of the component and to guarantee a good surface finish for the boundary layer contour. The samples were prepared using two different process parameter sets, which are listed in Table 1. For the edge layer contour, a double exposure was chosen.

For understanding the influence of the building space orientation on the tensile and compressive strength, AlSi10Mg specimens were prepared in five different building space orientations both for the tensile tests and for the compression tests. The polar angle $\Phi$ varied for the inclination to the layering and the azimuth angle $\Theta$ for the inclination in gas flow direction. Table 2 summarises the number of samples and configurations tested. The nomenclature is in accordance to the standardization of samples for comprehensive experiments proposed by Buschermöhle et al. [29], (Fig. 2).

\subsection{Post-heat treatment}

In a previous study, the influence of heat treatment on the microstructure and hardness of additively manufactured $\mathrm{AlSi} 10 \mathrm{Mg}$ samples were investigated [24]. It was found that a post-heat treatment results in a homogenization of the hardness. A distinct tendency for failure caused by varying aging conditions is avoided by eliminating the fluctuations in hardness. Thereby reducing the effects of different dwell times in the building space at increased temperatures and the precipitation hardening associated with the process. For this purpose, the $\mathrm{AlSi} 10 \mathrm{Mg}$ samples were annealed for $4 \mathrm{~h}$ at $170{ }^{\circ} \mathrm{C}$ in a controlled furnace in air prior to mechanical testing, after removal from the base plate, and cooled down to room temperature.

\subsection{Chemical analysis and determination of density}

From the measured chemical composition of the components (SPECTROMAXx, SPECTRO Analytical Instruments $\mathrm{GmbH}$ ), the maximum theoretical density was calculated. A set of six samples from the compressive samples was weighed for each building space orientation (processed condition) in air and under water (Archimedes' principle). It should be noted that the water contained a small number of additives to reduce the surface tension of the fluid and improve the reliability of the measurement.

Table 1 Applied process parameters for the processing of AlSi10Mg by selective laser melting

\begin{tabular}{lcllll}
\hline & $\begin{array}{l}\text { Scanning } \\
\text { speed } \\
(\mathrm{mm} / \mathrm{s})\end{array}$ & $\begin{array}{l}\text { Laser } \\
\text { power } \\
(\mathrm{W})\end{array}$ & $\begin{array}{l}\text { Hatch } \\
\text { spacing } \\
(\mathrm{mm})\end{array}$ & $\begin{array}{l}\text { Scan vec- } \\
\text { tor }(\mathrm{mm})\end{array}$ & $\begin{array}{l}\text { Rotation } \\
\text { angle }\left(^{\circ}\right)\end{array}$ \\
\hline Contour & 600 & 300 & - & - & - \\
Core & 1150 & 350 & 0.17 & 10 & 67 \\
\hline
\end{tabular}




\subsection{Tensile and compression tests}

The tensile and compression tests were carried out on a Zwick Roell type Z100 testing rig with load capability force of $100 \mathrm{kN}$. Before examination, each sample was deburred with abrasive paper (Kingspor KL361JF, 320 grit, $25 \mathrm{~mm}$ wide) and the side faces were smoothed. For loading and destructive material tests, it is recommended to remove these crack-initiating factors [30]. In the tensile tests, the change in length was measured with a BTC-EXMULTI.010 multiextensometer. Furthermore, the modulus of elasticity in the linear elastic range was determined for each specimen. For this, the specimen was loaded five times up to $100 \mathrm{MPa}$ and the Young's modulus was determined for each loading yielding an average value. Then a complete tensile test until failure was performed to determine yield strength $R_{\mathrm{p} 0.2}$, tensile strength $R_{\mathrm{m}}$ and elongation at failure $A_{\mathrm{t}}$, according to DIN EN ISO 6892-1: 2017-02. During the compression tests, according to DIN 50106, the specimens were continuously deformed until a specified minimum height was reached. In the linear elastic range, the compressive modulus of elasticity and the compressive yield strength $R_{\mathrm{dp}}$ were determined. Strain was recorded by a fine-strain extensometer with an initial length of $10 \mathrm{~mm}$ positioned at the centre part of the specimen to obtain the deformation values from specimen regions subjected to a uniaxial stress state only.

\section{Results and discussion}

\subsection{Chemical analysis}

The spectral analysis was performed on machined samples to obtain the chemical composition of the bulk material. Six measurements were performed from which averaged results were determined, see Table 3. Based on the composition, the theoretical density of $2.654 \mathrm{~g} / \mathrm{cm}^{3}$ was calculated [31]. It should be mentioned that the determined composition corresponded with the alloy composition specifications.

\subsection{Density based on Archimedes principle}

For the density evaluation according to the Archimedes' principle, the samples were weighed in air and under water. The average results for the density and volume porosity are given in Table 4. It can be concluded that the samples
Table 2 Number of tensile and compression specimens and their orientation

\begin{tabular}{lllllllllll}
\hline & \multicolumn{9}{c}{ Tensile specimens } & \multicolumn{7}{c}{ Compression specimens } \\
\hline Number of samples & 3 & 3 & 3 & 3 & 3 & 7 & 6 & 7 & 7 & 8 \\
Polar angle $\Phi$ & $0^{\circ}$ & & $30^{\circ}$ & $45^{\circ}$ & $90^{\circ}$ & $0^{\circ}$ & $30^{\circ}$ & $45^{\circ}$ & $75^{\circ}$ & $90^{\circ}$ \\
Azimuth angle $\Theta$ & $0^{\circ}$ & $90^{\circ}$ & $0^{\circ}$ & $0^{\circ}$ & $0^{\circ}$ & $0^{\circ}$ & $0^{\circ}$ & $0^{\circ}$ & $0^{\circ}$ & $0^{\circ}$ \\
\hline
\end{tabular}

(a) Tensile specimen

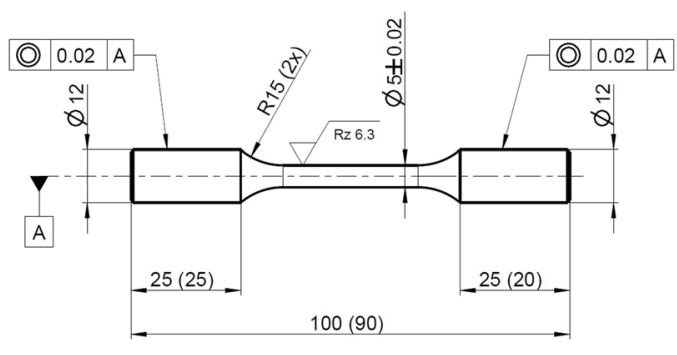

(b) Compression specimen

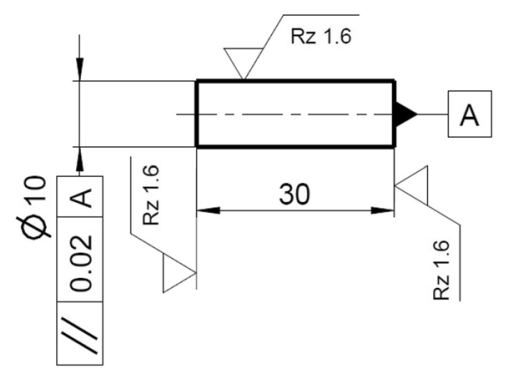

Fig. 2 Schematic drawing of the tensile and compression specimens machined from additively manufactured AlSi10Mg samples
Table 3 Average chemical composition in mass percentage

\begin{tabular}{llllllll}
\hline $\mathrm{Al}^{1}$ & STDEV & $\mathrm{Si}$ & STDEV & $\mathrm{Fe}$ & STDEV & $\mathrm{Cu}$ & STDEV \\
88.3696 & 0.2553 & 11.1138 & 0.2501 & 0.1777 & 0.0051 & 0.0044 & 0.0030 \\
$\mathrm{Mn}$ & STDEV & $\mathrm{Mg}$ & STDEV & $\mathrm{Ni}$ & STDEV & $\mathrm{Ti}$ & STDEV \\
0.0064 & 0.0014 & 0.2405 & 0.0053 & 0.0051 & 0.0016 & 0.0101 & 0.0027 \\
$\mathrm{Ca}$ & STDEV & $\mathrm{Ga}$ & STDEV & $\mathrm{Na}$ & STDEV & $\mathrm{V}$ & STDEV \\
0.0038 & 0.0005 & 0.0116 & 0.0004 & 0.0003 & 0.0002 & 0.0046 & 0.0008 \\
\hline
\end{tabular}

${ }^{1}$ The measured aluminium content was slightly modified to obtain a total element content of $100 \%$ 
Table 4 Density and volume porosity measured using the Archimedes principle

\begin{tabular}{lllll}
\hline $\begin{array}{l}\text { Building direc- } \\
\text { tion } \\
\Phi / \Theta(\%)\end{array}$ & Density $\rho\left(\mathrm{g} / \mathrm{cm}^{3}\right)$ & $\begin{array}{l}\text { STDEV } \\
\text { Volume } \\
\text { porosity } \\
(\%)\end{array}$ & STDEV \\
\hline $0 / 0$ & 2.650 & 0.001 & 0.15 & 0.054 \\
$30 / 0$ & 2.651 & 0.001 & 0.12 & 0.045 \\
$45 / 0$ & 2.650 & 0.001 & 0.15 & 0.036 \\
$75 / 0$ & 2.650 & 0.002 & 0.15 & 0.059 \\
$90 / 0$ & 2.652 & 0.001 & 0.09 & 0.049 \\
Average & 2.651 & 0.001 & 0.13 & 0.053 \\
\hline
\end{tabular}

produced are based on high quality with regard to their relative density volume porosity.

\subsection{Tensile strength and compressive behaviour}

The results of the tensile test are shown in Table 5. It is evident that the configuration with the lower built height, a layer orientation parallel to the loading direction and an orientation perpendicular to the gas flow direction $\left(0^{\circ} / 0^{\circ}\right)$ showed high tensile strength and ductility. One of the main arguments for the lower strength of inclined specimens is the phenomenon of an increasing probability of irregularities and voids with an increasing number of layers. However, this is not necessarily synonymous with an increased degree of porosity as shown in Table 4 . However, it has been demonstrated that the connections between individual laser traces and layers predominantly alter the anisotropic properties [28, $32,33]$. The alignment of the layers, starting from $45^{\circ}$, with increasing polar angles leads to lower strength with low ductility. This behaviour is directly related to the coincidence of the layer orientation with the maximum shear forces that occur at an angle of $45^{\circ}$ to the tensile load and thus promote sliding and breaking between adjacent layers. The lowest ductility was shown for the vertical orientation of the layer in relation to the direction of loading.

An interesting phenomenon is the deviation between the configurations $0^{\circ} / 0^{\circ}$ and $0^{\circ} / 90^{\circ}$. Yield strength was $7.11 \%$, tensile strength was $9.23 \%$ and ductility was $4.4 \%$ lower in case of the $0^{\circ} / 90^{\circ}$ configuration. The required space and building height during production were the same and both configurations had the same initial condition in terms of their load versus shift orientation. The only difference between these two configurations was the variation of the orientation of the longitudinal axis of the sample in the XY-plane, so the samples with the $0^{\circ} / 0^{\circ}$ orientation were perpendicular to the gas flow direction and the $0^{\circ} / 90^{\circ}$ configuration parallel to it. These deviations can be due to two possible causes. On the one hand, the irradiation pattern applied changes, which generally begins at a defined point for each individual cross section and on the other hand it moves in different directions along the cross section to be irradiated [25]. This creates different segment sizes of the individual irradiation cells. Further, the inhomogeneities of the environmental conditions caused by the gas flow over the powder bed lead to inhomogeneities of the surface condition [34]. This affects the subsequent recoating and irradiation process. The unidirectional gas flow causes not only an inhomogeneous surface condition, but also an inhomogeneous temperature field, which leads to different cooling rates [35]. In combination, these effects lead to obvious differences between the configurations.

Comparing the tensile strength results with those from earlier investigations of Hitzler et al. [25], Sert et al. [30] with this current study, (see Fig. 3), the results are in a similar range (the differences between the process parameters were shown in Table 7 in the "Appendix"). All cases show a tendential decrease in yield strength and ultimate tensile strength at a polar angle of $0^{\circ}-45^{\circ}$, corresponding to a brittle shear fracturing between consecutive layers. Slightly lower strength values reported by Hitzler et al. [25] for the inclined samples can be explained by their premature failure caused by height-dependent deviations in their precipitation hardening state.

The lower Young's modulus obtained by Sert et al. [30] in is believed to be a result of testing it close to their asfabricated condition, without machining the samples and removing the sub-surface porosities which may be present between the contour and core irradiation.

The compression tests showed remarkably high stiffness results in all configurations, see Table 6. Due to the arbitrary occurrence of buckling, the maximum stress results
Table 5 Averaged results for mechanical properties, tensile test according DIN EN ISO 6892-1: 2017-02, tested at room temperature

\begin{tabular}{|c|c|c|c|c|c|c|c|c|}
\hline \multirow{2}{*}{$\begin{array}{l}\text { Building } \\
\text { direction } \\
\Phi / \Theta\left({ }^{\circ}\right)\end{array}$} & \multicolumn{2}{|c|}{$\begin{array}{l}\text { Young's modulus } E \\
(\mathrm{GPa})\end{array}$} & \multicolumn{2}{|c|}{$\begin{array}{l}\text { Yield strength } R \mathrm{p}_{0.2} \\
(\mathrm{MPa})\end{array}$} & \multicolumn{2}{|c|}{$\begin{array}{l}\text { Ultimate tensile } \\
\text { strength } R \mathrm{~m}(\mathrm{MPa})\end{array}$} & \multicolumn{2}{|c|}{$\begin{array}{l}\text { Elongation at failure } \\
A_{\mathrm{t}}(\%)\end{array}$} \\
\hline & Average & STDEV & Average & STDEV & Average & STDEV & Average & STDEV \\
\hline $0 / 0$ & 73.5 & 2.7 & 225 & 6 & 364 & 5 & 6.5 & 0.2 \\
\hline $0 / 90$ & 73.2 & 3.2 & 209 & 9 & 348 & 9 & 5.9 & 0.7 \\
\hline $30 / 0$ & 78.5 & 1.5 & 210 & 3 & 349 & 15 & 4.4 & 1.4 \\
\hline $45 / 0$ & 76.9 & 3.1 & 192 & 8 & 344 & 9 & 5.9 & 0.9 \\
\hline $90 / 0$ & 74.8 & 1.0 & 205 & 5 & 377 & 5 & 3.3 & 0.2 \\
\hline
\end{tabular}



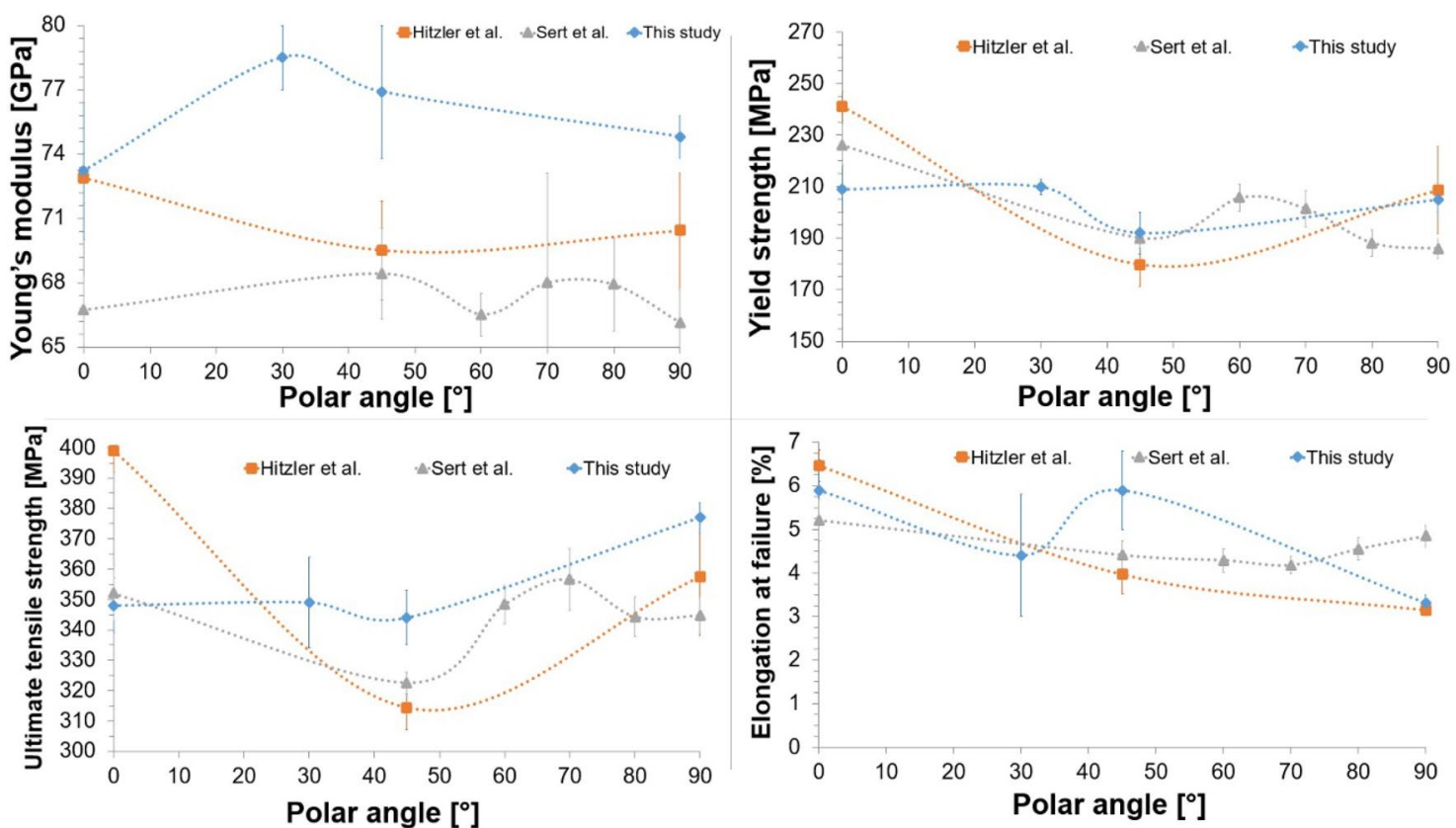

Fig. 3 Summary of tensile strength results from early investigations of Hitzer et al., Sert et al. and this study (Table 7)

Table 6 Averaged results for mechanical properties, compression tests at room temperature

\begin{tabular}{|c|c|c|c|c|}
\hline \multirow[t]{2}{*}{$\begin{array}{l}\text { Building direc- } \\
\text { tion } \Phi / \Theta\left(\%{ }^{\circ}\right)\end{array}$} & \multicolumn{2}{|c|}{$\begin{array}{l}\text { Young's modulus } E \\
(\mathrm{GPa})\end{array}$} & \multicolumn{2}{|c|}{$\begin{array}{l}\text { Yield strength } R_{\mathrm{dp}} \\
(\mathrm{MPa})\end{array}$} \\
\hline & Average & STDEV & Average & STDEV \\
\hline $0 / 0$ & 74.2 & 2.2 & 227 & 14 \\
\hline $30 / 0$ & 73.5 & 2.4 & 218 & 9 \\
\hline $45 / 0$ & 77.8 & 1.7 & 243 & 8 \\
\hline $75 / 0$ & 79.8 & 1.1 & 280 & 13 \\
\hline $90 / 0$ & 79.1 & 0.5 & 300 & 9 \\
\hline
\end{tabular}

could not be recorded and are, therefore, not included in this study.

The compressive yield strength in the $75^{\circ}$ and $90^{\circ}$ configurations has high values (Fig. 4). It is generally known that although porosity is a major flaw in SLM materials, it is not a key factor in compressive loads. This is because the nature of the load tends to close the pores and solidify the defective areas as long as the porosity is minimal. In contrast, under tensile loading, the pores begin to expand, coalesce and spread in the form of cracks that lead to failure. Reviewing the obtained results, it can be concluded that the influence of porosity may be related to the layer orientation to the direction of loading. This would mean that for specimens with a layer orientation parallel to the direction of loading, the influence of the flaws is greater and thus sliding of the layers is stimulated than for specimens with a perpendicular layer orientation. This would explain the high compressive yield strength of the $75^{\circ}$ and $90^{\circ}$ specimens. If the results are compared with the related study from Aboulkhair et al. [27], it can be underlined that the results of the $90^{\circ}$ specimens show a similar tendency of the compressive yield strength.

The qualitative stress-strain relationship (tension/compression) for the different configurations is shown in Fig. 4. It can be seen that the tendency of the compression and tensile modulus of elasticity is the same in all configurations. With regards to the flow criterion, the results for both, the tensile and compressive yield strength for the $0^{\circ} / 0^{\circ}, 30^{\circ} / 0^{\circ}$ and $45^{\circ} / 0^{\circ}$ configurations were in a similar range. The longer compression specimens tested in [36] show a higher compression modulus of elasticity of 5-8\%. Due to the larger width to length ratio (1:5), the uniaxial load component is larger, which leads to more accurate results. However, the main disadvantage of these specimens was their tendency to buckle, none of the specimens tested in [36] could be tested to failure. Therefore, no data could be collected for the compressive strength. The width to length ratio (1:3) used in this study also tended to buckle and, therefore, no data on compressive strength could be obtained. To determine the compressive strength, a width to length ratio of $1: 2$ is usually recommended to ensure that no buckling occurs.

In the as-built condition, the microstructure is governed by a fine cellular structure comprised of supersaturated $\alpha$-Al grains and an interconnected network of the $\mathrm{Si}$ eutectic phases [37]. The connecting areas between adjacent scan tracks, including the melt pool boundary and the 
Fig. 4 Tensile and compressive stress-strain diagram

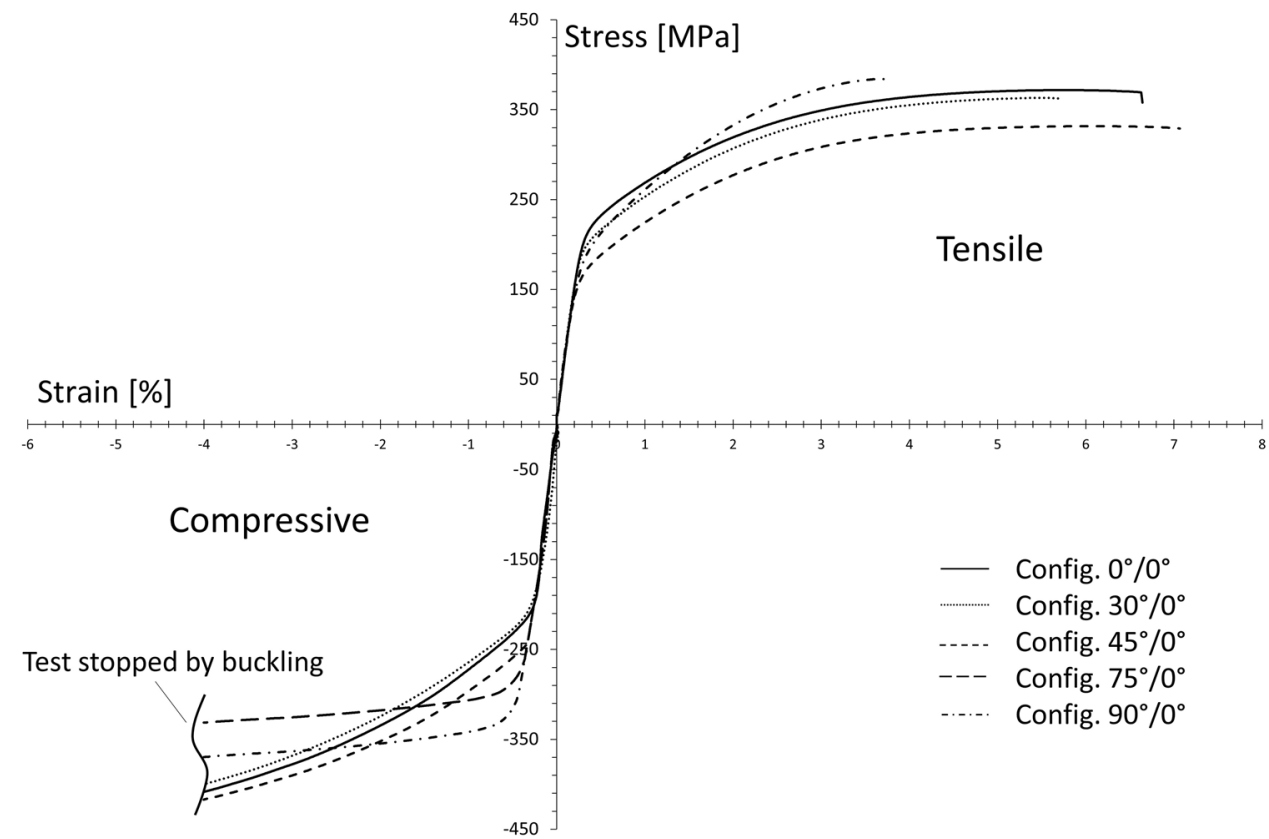

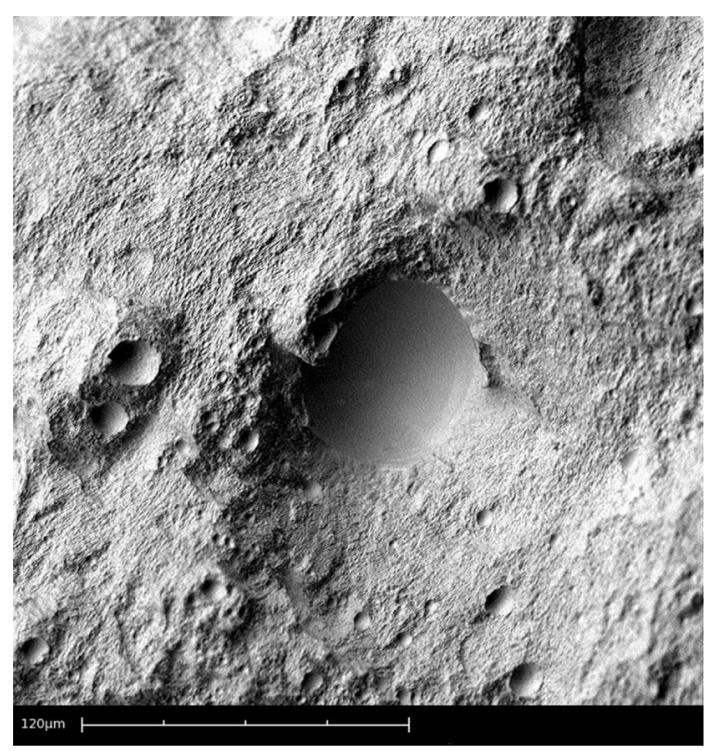

Fig. 5 SEM image of the fracture surface of a $45^{\circ}$ polar angle specimen

heat-affected zone of the prior fabricated track or layer, exhibit a coarser microstructure, affecting both $\alpha-\mathrm{Al}$ crystals and Si particles [28]. Nano-indentations have confirmed that these regions are inferior in hardness and past studies on static uniaxial material tests suggested that these regions promote brittle shear fracturing, leading to the drop in yield strength at $45^{\circ}$ polar angle and the reduction in elongation at failure from $0^{\circ}$ to $90^{\circ}$ polar angle (Fig. 5) $[25,26$, 36]. It should be noted that due to the rotation of the scan track pattern after every layer, the aforementioned effect of these zones is far more evident in the repetitive layering. Apart from the macroscopic anisotropy reasoned in the layering and the difficulties which arise as a result, the static mechanical properties achieved in L-PBF-fabricated AlSi are superior to their cast counterparts. This is a result which originates from the same principle, mainly the rapid cooling of the melt to a solid, which forms the fine cellular structure, followed by the rapid quenching of the solidified material from solidification temperature to the process preheating temperature. These quenching rates cannot be reproduced by means of heat treatments and, therefore, lead to a maximum of dissolved alloying elements in the oversaturated $\alpha$-Al crystals [38]. This, in turn, benefits the solid solution hardening, but more importantly, the possible precipitation hardening of these alloys, whereby the artificial aging of the just solidified and quenched material starts instantaneously during the process, due to the common process temperatures of around $200{ }^{\circ} \mathrm{C}$ being in the regime of artificial aging temperatures of $\mathrm{Al}-\mathrm{Si}-\mathrm{Mg}$ alloys. An immediate artificial aging has the added benefit, that the stoichiometry of the formed clusters increases the effectiveness of the precipitation hardening, an effect which is well known from direct-aging heat treatments in cast $\mathrm{Al}-\mathrm{Si}-\mathrm{Mg}$ [39-41].

\section{Conclusions}

In this study, the mechanical properties of selective lasermelted AlSi10Mg were investigated. It could be shown that the material characteristics for Young's modulus, yield strength and tensile strength are more or less independent of direction. The modulus of elasticity in compression showed 
the same tendency as the modulus of elasticity in tension and ranged between 73.5 and $79.8 \mathrm{GPa}$. Furthermore, it was found that the compressive proportional limit and the yield strength from the tensile test showed similar values for the configurations $0^{\circ} / 0^{\circ}, 30^{\circ} / 0^{\circ}$ and $45^{\circ} / 0^{\circ}$, in these cases, identical directional tendencies and thus a more or less isotropic behaviour with scattering related to the tensile and compressive properties. The configurations $75^{\circ} / 0^{\circ}$ and $90^{\circ} / 0^{\circ}$ showed higher values (280 MPa and $300 \mathrm{MPa}$ ) at the pressure proportional limit compared to the yield strengths from the tensile test. This was explained by the influence of flaws/ porosity on the compressive load, but will be further investigated. In this study, among other things, the determination of the modulus of elasticity was aimed at, whereupon a width/ length ratio of 1:3 was chosen to allow a uniaxial stress state. Due to this ratio, buckling occurred in the course of the tests, which meant that the compressive strengths could not be determined.

Acknowledgements Open Access funding provided by Projekt DEAL.

\section{Compliance with ethical standards}

Conflict of interest The authors declare that there is no conflict of interest.

Open Access This article is licensed under a Creative Commons Attribution 4.0 International License, which permits use, sharing, adaptation, distribution and reproduction in any medium or format, as long as you give appropriate credit to the original author(s) and the source, provide a link to the Creative Commons licence, and indicate if changes were made. The images or other third party material in this article are included in the article's Creative Commons licence, unless indicated otherwise in a credit line to the material. If material is not included in the article's Creative Commons licence and your intended use is not permitted by statutory regulation or exceeds the permitted use, you will need to obtain permission directly from the copyright holder. To view a copy of this licence, visit http://creativecommons.org/licenses/by/4.0/.

\section{Appendix}

This section contains further details and data to supplement the given information and evaluation in the main section and to allow for repetition and thorough comparisons.

See Table 7.

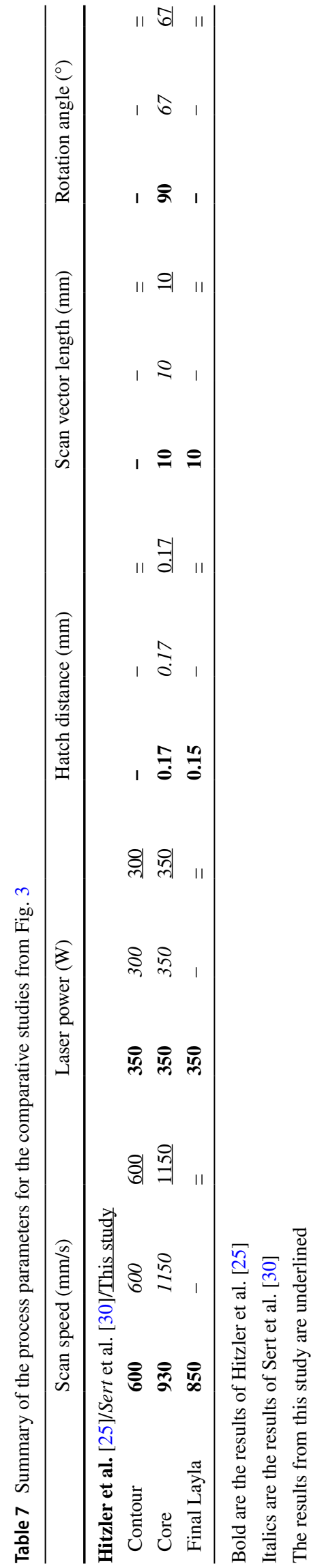




\section{References}

1. Gu D (2015) Laser additive manufacturing of high-performance materials. Springer-Verlag, Berlin

2. Bourell D et al (2002) Powder densification maps in selective laser sintering. Adv Eng Mater 4(9):663-669

3. Beal VE et al (2006) The effect of scanning strategy on laser fusion of functionally graded $\mathrm{H} 13 / \mathrm{Cu}$ materials. Int J Adv Manuf Technol 30(9-10):844-852

4. Hitzler L, Merkel M, Hall W, Öchsner A (2018) A review of metal fabricated with laser- and powder-bed based additive manufacturing techniques: process, nomenclature, materials, achievable properties, and its utilization in the medical sector. Adv Eng Mater. https://doi.org/10.1002/adem.201700658

5. Weingarten C et al (2015) Formation and reduction of hydrogen porosity during selective laser melting of AlSi10Mg. J Mater Process Technol 221:112-120

6. Buchbinder D et al (2010) Abschlussbericht-Generative Fertigung von Aluminiumbauteilen für die Serienproduktion, 01RIO639A-D, BMBF. In: Projekt-AluGenerativ. Fraunhofer ILT: Aachen, Germany

7. Buchbinder D et al (2015) Selective laser melting of aluminum die-cast alloy-correlations between process parameters, solidification conditions, and resulting mechanical properties. J Laser Appl 27(S2):S29205

8. Frazier WE (2014) Metal additive manufacturing: a review. J Mater Eng Perform 23(6):1917-1928

9. Beese AM, Carroll BE (2015) Review of mechanical properties of Ti-6Al-4V made by laser-based additive manufacturing using powder feedstock. JOM 68(3):724-734

10. Abele E et al (2015) Selective laser melting for manufacturing of thin-walled porous elements. J Mater Process Technol 215:114-122

11. Wang D et al (2012) Study on energy input and its influences on single-track, multi-track, and multi-layer in SLM. Int J Adv Manuf Technol 58(9-12):1189-1199

12. Su X, Yang Y (2012) Research on track overlapping during selective laser melting of powders. J Mater Process Technol 212(10):2074-2079

13. Prashanth KG, Eckert J (2017) Formation of metastable cellular microstructures in selective laser melted alloys. J Alloy Compd 707:27-34

14. Barriobero-Vila $P$ et al (2018) Peritectic titanium alloys for 3D printing. Nat Commun 9(1):3426

15. Awd M, Tenkamp J, Hirtler M, Siddique S, Bambach M, Walther F (2017) Comparison of microstructure and mechanical properties of scalmalloy ${ }^{\circledR}$ produced by selective laser melting and laser metal deposition. Materials (Basel). https://doi.org/10.3390/ma11010017

16. Zener CM, Siegel S (1949) Elasticity and anelasticity of metals. J Phys Colloid Chem 53(9):1468-1468

17. Olakanmi EO, Cochrane RF, Dalgarno KW (2015) A review on selective laser sintering/melting (SLS/SLM) of aluminium alloy powders: processing, microstructure, and properties. Prog Mater Sci 74:401-477

18. Li XP et al (2015) A selective laser melting and solution heat treatment refined $\mathrm{Al}-12 \mathrm{Si}$ alloy with a controllable ultrafine eutectic microstructure and 25\% tensile ductility. Acta Mater 95:74-82

19. Chen $\mathrm{Y}$ et al (2018) Distinction of corrosion resistance of selective laser melted $\mathrm{Al}-12 \mathrm{Si}$ alloy on different planes. J Alloy Compd 747:648-658

20. Liu YJ et al (2018) Gradient in microstructure and mechanical property of selective laser melted AlSi10Mg. J Alloy Compd 735:1414-1421

21. Yang Y et al (2018) Improved corrosion behavior of ultrafinegrained eutectic $\mathrm{Al}-12 \mathrm{Si}$ alloy produced by selective laser melting. Mater Des 146:239-248
22. Suryawanshi J et al (2016) Simultaneous enhancements of strength and toughness in an $\mathrm{Al}-12 \mathrm{Si}$ alloy synthesized using selective laser melting. Acta Mater 115:285-294

23. Bi J et al (2019) Effect of process parameters on formability and surface quality of selective laser melted $\mathrm{Al}-\mathrm{Zn}-\mathrm{Sc}-\mathrm{Zr}$ alloy from single track to block specimen. Opt Laser Technol 118:132-139

24. Sert E, Hitzler L, Heine B, Merkel M, Werner E, Öchsner A (2019) Influence of the heat treatment on the microstructure and hardness of additively manufactured AlSi $10 \mathrm{Mg}$ samples. Pract Metallogr 56(2):91-105. https://doi.org/10.3139/147.110560

25. Hitzler L et al (2017) Direction and location dependency of selective laser melted AlSi10Mg specimens. J Mater Process Technol 243:48-61

26. Ming T (2017) Inclusions, porosity, and fatigue of AlSi10Mg parts produced by selective laser melting. Figshare. Thesis. https://doi. org/10.1184/R1/6720185.v1

27. Aboulkhair NT (2016) Additive manufacture of an aluminium alloy: processing, microstructure, and mechanical properties. University of Nottingham, Nottingham

28. Prashanth KG et al (2014) Microstructure and mechanical properties of Al-12Si produced by selective laser melting: effect of heat treatment. Mater Sci Eng A 590:153-160

29. Buschermöhle H (1996) Vereinheitlichung von Proben für Schwingversuche: Vorhaben 198 ; Abschlußbericht; Beginn der Arbeiten: 01.01.1995; Ende der Arbeiten: 31.12.1995. Frankfurt a.M: FKM. https://books.google.de/books?id=muSyAQAACAAJ

30. Sert E et al (2019) Tensile strength performance with determination of the Poisson's ratio of additively manufactured AlSi10Mg samples. Materialwiss Werkstofftech 50(5):539-545

31. LENNTECH (2015) Chemische Elemente geordnet nach der Dichte. https://www.lenntech.de/data-pse/dichte.htm. Accessed 26 Oct 2015

32. Zhao J et al (2018) Effect of building direction on porosity and fatigue life of selective laser melted AlSi12Mg alloy. Mater Sci Eng, A 729:76-85

33. Reschetnik W et al (2016) Fatigue crack growth behavior and mechanical properties of additively processed EN AW-7075 aluminium alloy. Proc Struct Integr 2:3040-3048

34. Hitzler L et al (2017) Position dependent surface quality in selective laser melting. Materialwiss Werkstofftech 48(5):327-334

35. Dadbakhsh S, Hao L, Sewell N (2012) Effect of selective laser melting layout on the quality of stainless steel parts. Rapid Prototyp J 18(3):241-249

36. Hitzler $\mathrm{L}$ et al (2018) Compressive behaviour of additively manufactured AlSi10Mg. Materialwiss Werkstofftech 49(5):683-688

37. Rafieazad M, Mohammadi M, Nasiri AM (2019) On microstructure and early stage corrosion performance of heat treated direct metal laser sintered AlSi10Mg. Additive Manuf 28:107-119

38. Hitzler L, Hafenstein S, Mendez Martin F, Clemens H, Sert E, Öchsner A, Merkel M, Werner E (2020) Heat treatments and critical quenching rates in additively manufactured $\mathrm{Al}-\mathrm{Si}-\mathrm{Mg}$ alloys. Materials 13:720. https://doi.org/10.3390/ma13030720

39. Hafenstein S, Werner E (2019) Pressure dependence of age-hardenability of aluminum cast alloys and coarsening of precipitates during hot isostatic pressing. Mater Sci Eng A 757:62-69

40. Hafenstein S, Werner E (2019) Direct aging of a hot isostatically pressed A356 aluminum cast alloy. Mater Sci Eng A 768:138417. https://doi.org/10.1016/j.msea.2019.138417

41. Hafenstein S (2019) HeißHeißisostatisches pressen von aluminiumgusslegierungen mit integrierter wärmebehandlung. Thesis. https://doi.org/10.1007/978-3-658-25600-5

Publisher's Note Springer Nature remains neutral with regard to jurisdictional claims in published maps and institutional affiliations. 